\author{
De la Torre Oliver, Francisco. \\ Profesor, Universitat Politècnica de València, Pintura, CIAE.
}

\title{
Imágenes de otros mundos. La alianza entre pintura y videojuego
}

\section{Images from other worlds. The alliance between painting and videogame}

TIPO DE TRABAJO: Comunicación.

\author{
PALABRAS CLAVE
}

Videojuego, Pintura digital, Pintura, Concept Artist, Red Dead Redemption 2, Hudson River School.

KEY WORDS

Videogame, Digital painting, Painting, Concept Artist, Red Dead Redemption 2, Hudson River School.

\section{RESUMEN}

La industria del videojuego ha encontrado en la pintura el medio donde visualizar sus propios mundos ¿Podría suponer el desarrollo de los videojuegos AAA una revalorización de la pintura ilusionista convirtiendo al concept artist en el nuevo pintor del siglo XXI?

El arte tiene la capacidad de representar una imagen del mundo coherente con los planteamientos ideológicos desde los que se desarrolla. La pintura ha satisfecho, a lo largo de su historia, la necesidad del hombre de crear una imagen del mundo, una representación del mundo e imaginar nuevos mundos. Una práctica que conectaría con el concepto de Mundo abierto desarrollado en los videojuegos actuales.

Realizaremos una breve revisión de la representación de mundos en la pintura a través de su historia, desde la idealización en la Edad Media a los planteamientos experimentales de la vanguardia artística del siglo XX.

Actualmente, el concept artist representaría al agente de la industria del entretenimiento encargado de desarrollar la visualización del mundo en el que se desarrollan los videojuegos. La labor de encarnar estas imágenes se realiza a través de la pintura, mediante técnicas tradicionales o digitales. De este modo, se estaría produciendo una revisión de las claves pictóricas clásicas con el objetivo de resolver problemas de representación actuales, replanteando las relaciones entre arte y diseño o cultura y entretenimiento.

Para profundizar en estas cuestiones, planteamos estudiar el caso de Red Dead Redemption 2 y su relación con la Hudson River School.

ABSTRACT

The videogame industry has found in painting the means to visualize its own worlds. Could the development of AAA videogames imply a revaluation of naturalist painting, turning the concept artist into the new painter of the 21st century?

Art has the capacity to represent an image of the world coherent with the ideological approaches from which it develops. Painting has satisfied, throughout its history, man's need to create an image of the world, a representation of the world and imagine new worlds. A practice that would connect with the concept of Open World developed in current video games.

We will make a brief review of the representation of worlds in painting through its history, from the idealization in the Middle Ages to the experimental approaches of the artistic avant-garde of the 20th century.

Currently, the concept artist would represent the agent of the entertainment industry in charge of developing the visualization of the world in which videogames are developed. The work of embodying these images is done through painting, using traditional or digital 
techniques. In this way, a review of the classic pictorial keys with the aim of solving current representation problems, rethinking the relationship between art and design or culture and entertainment, would be taking place.

To delve into these issues, we propose to study the case of Red Dead Redemption 2 and its relationship with the Hudson River School.

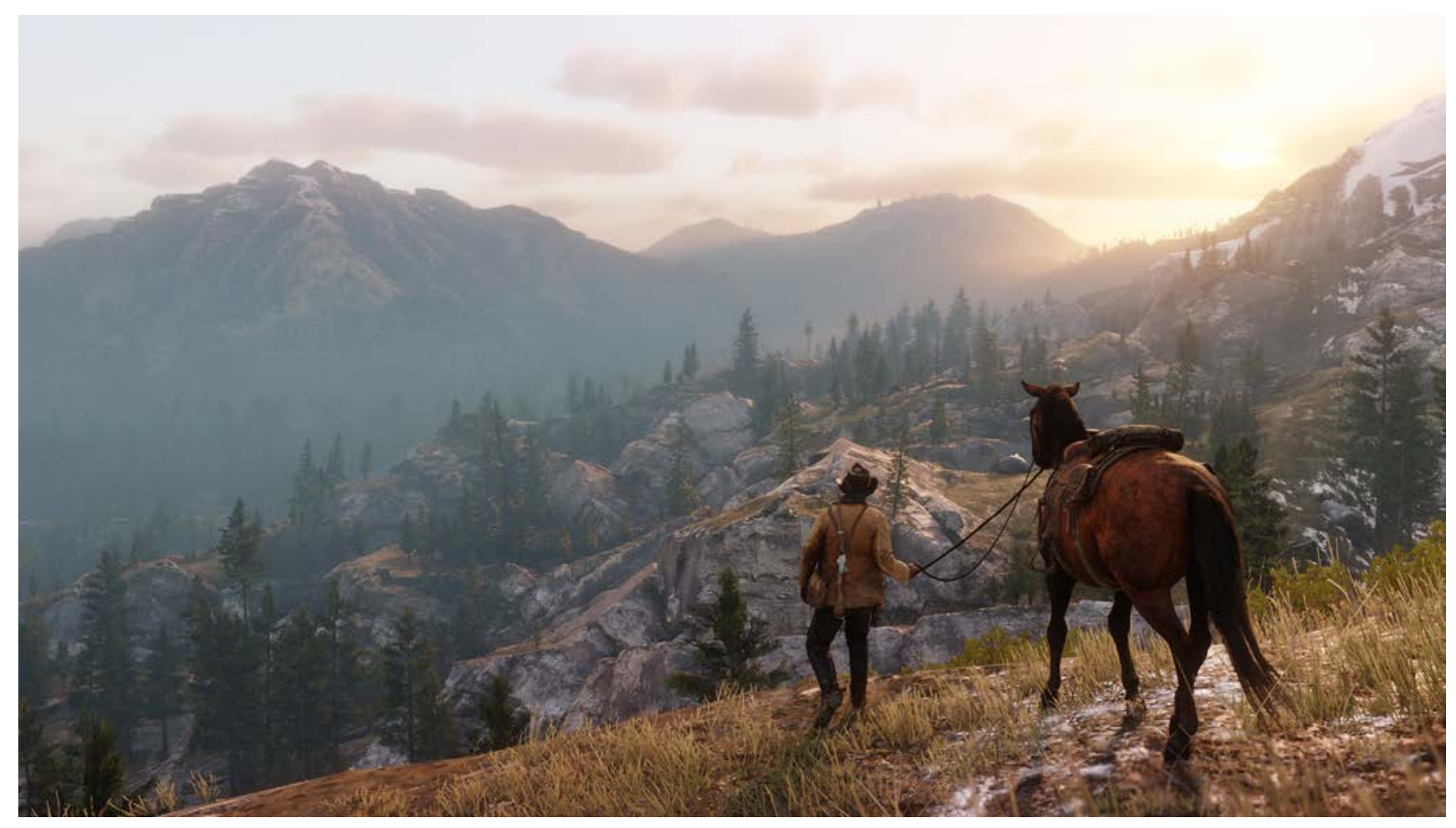

Figura 1. [Captura de pantalla], "Red Dead Redemption 2", Rockstar Games, 2018. (Fuente: https://www.igdb.com/games/red-dead-redemption-2/presskit).

\section{INTRODUCCIÓN}

A partir del análisis de la influencia de la pintura de la River Hudson School en la concepción del mundo donde se desarrolla el icónico videojuego Red Dead Redemption 2, planteamos una reflexión sobre la creación de imágenes de mundos en el espacio ilusionista de la pintura, así como su implementación en la producción de la industria del entretenimiento por parte del concept artist.

\section{METOdOLOGÍA}

A través del estudio de diferentes referentes teóricos abordaremos algunos de los conceptos que han surgido a partir de nuestro objeto de estudio, para de este modo crear un marco teórico que nos ayude a profundizar en el análisis y nos posibilite la obtención de conclusiones.

\section{DESARROLLO}

"Si cada cultura humana crea su propio espacio plástico" (Gubern, 1996, p. 32), el concepto de imagen diseñada en el Renacimiento será el que conforme, de una manera decisiva, la imagen del mundo moderno. Y será, en ese momento, donde Heidegger (1996) sitúe la concepción del mundo como imagen en su texto La época de la imagen del mundo. "El mundo entendido como imagen" implicaría, ante todo, una apropiación y asimilación de la realidad que tendría lugar en el medio de la imagen y como imagen. "La imagen del mundo, da igual lo que muestre, en todo caso presenta un mundo conmensurable cuyo espanto y belleza no puede por principio exigir demasiado del espectador" (Mayer, 1996, p. 75). 
Pero, como señala Goodman, el mundo que entiende por real el hombre de la calle sería el que habría construido en un bricolaje barato a partir de diversos fragmentos de la tradición científica y artística desarrollada como estrategia para su supervivencia, pues la realidad de un mundo, al igual que acontece en el realismo de una pintura, es en gran medida una cuestión de hábitos (Goodman, 1995, p. 41). Pero ¿Qué es real? Una cuestión sobre la que las hermanas Wachowski reflexionarían de manera ilustrativa en la icónica Matrix a final de siglo XX. "¿De qué modo definirías real?" Le plantea Morfeo a Neo, "Si te refieres a lo que puedes sentir, a lo que puedes oler, a lo que puedes saborear y ver, lo real podrían ser señales eléctricas interpretadas por tu cerebro" (Wachowski, 1999, 40:20 min.). Goodman está convencido que no existe ningún modo correcto de describir, pintar o percibir "El mundo" sino que existirían, más bien, muchos modos igualmente correctos, aunque pudieran entrar en conflicto, y por consiguiente "muchos mundos reales" (1995, p. 33).

En tal caso, si en el videojuego se plantea la creación de mundos, el análisis de estos mundos debería comenzar por abordar el complejo concepto de Mundo. Desde una visión científica nos estaríamos refiriendo al planeta Tierra, y a un sistema que integraría formas de pensar desde una visión humanista, como señala Sánchez Coterón (2012), la noción de mundo también la emplearíamos para parcelar la historia en periodos concretos, como el mundo del Romanticismo, o para vincular distintos elementos alrededor de un mismo protagonista, el mundo de Chaplin (p. 54). La visión de este concepto poliédrico como composición de sujetos, objetos y estados que conforman sistemas de representación autónomos y particulares, será el punto de partida de los concept artists para realizar su trabajo. En esta línea de investigación debemos situar el trabajo de Wolf (2012), el intento de afrontar la historia de los mundos imaginarios y las razones que llevaron a sus autores a construirlos. Las narraciones ambientadas en mundos imaginarios proporcionarían una serie de recursos que otorgarían un mayor grado de libertad a sus creadores. Lo que Wolf define como mundos secundarios nos permitirían enfrentarnos de forma alternativa al primario, conformando un método de cuestionamiento de los valores asumidos por el público desde perspectivas diversas, desde la sátira al divertimento.

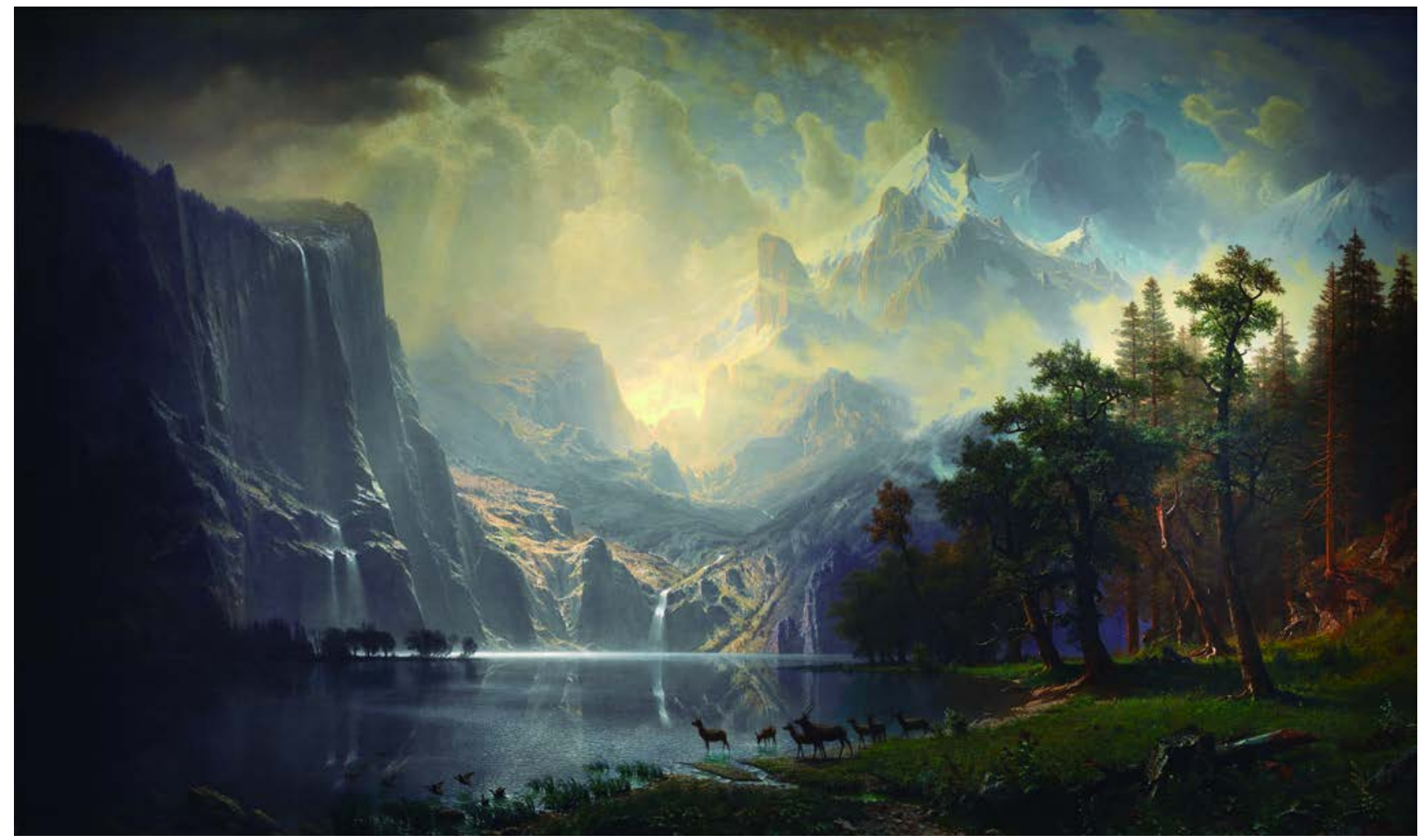

Figura 2. [Pintura], "Entre la Sierra Nevada, California ", Bierstadt, A., 1868, 244.5 x 366.7 cm. (Fuente: https://commons.wikimedia.org/wiki/Albert Bierstadt. Dominio público de Estados Unidos).

Actualmente, el estudio de los mundos imaginarios se afronta de un modo multidisciplinar desde campos tan diversos como la filosofía, la psicología o la religión, pero también desde la economía y los estudios cinematográficos y el videojuego. Estos mundos que nacieron en la literatura o la filosofía, como la Odisea o Kallipolis, se han desarrollado a través de los medios "abriendo portales a través de los cuales crecen en claridad y detalle, invitándonos a entrar y tentándonos a permanecer, tan vivos en nuestro pensamiento como nuestros propios recuerdos de la experiencia vivida" (Wolf, 2012, p. 13). En su opinión, la narración se ha convertido en el arte de construir un mundo que no se pueden explorar o agotar por completo en una sola obra o medio, ya que en su opinión "se pondría más energía en mapear el mundo que en habitarlo" (Wolf, 2012, p. 13). 
Autores postmodernos como David Lynch han manifestado su interés por construir mundos a los que nunca podrías ir a menos que los reproduzca en su película, "es la única constante del cine de Lynch: la existencia de más de un mundo" (Chion, 2003, p. 273). En el videojuego, las fronteras entre realidad y ficción se desdibujan en la virtualidad digital como sucede en la pintura surrealista donde la imagen es, y por ello "cuando se visualiza a través del sueño o de la imaginación, no cabe considerarla como una mera ilusión, sino como aquello de carácter maravilloso que constituye la otra parte de la realidad" (Jiménez, 2013, p. 23). Así, las imágenes podrían representar hechos participando de este modo en la creación de mundos de manera muy similar a como lo hacen las palabras, y en este sentido Goodman (1990) señala que "nuestra así llamada imagen cotidiana del mundo es el resultado de la conjunción de descripciones verbales y de representación de imágenes" (p. 142).

El ilusionismo renacentista resolvería las necesidades planteadas por el franciscano Roger Bacon en 1268 al papa Clemente IV, al señalar que "para convencer a los fieles de que los episodios sagrados contemplados eran verdaderos el arte religioso debería simular el espacio tridimensional", es decir hacer visible lo imaginado en la mente (Gubern, 1996, p. 109). También Breton defendería esta metáfora para los surrealistas, "me es imposible imaginar una pintura de un modo distinto a una ventana frente a la cual mi primera preocupación es saber a donde da" (Lahuerta, 2013, p. 35). Una disolución de los estados, aparentemente antagónicos del sueño y el mundo real en una especie de realidad absoluta que podríamos llamar surrealidad. Por tanto, como señala Gubern (1996), "la imagenescena hablaría el mismo lenguaje que los sueños y de ahí derivaría su capacidad paradójica, su turbador ilusionismo, su eficacia para la comunicación emocional, su sugestión libidinal y sus enormes potenciales para el engaño y la confusión" (p. 49). En este sentido, Dalí (2003) defendería la técnica ultrarretrógrada y subversiva de Meissonier, frente a Matisse y las tendencias abstractas, como el medio donde desarrollar su método crítico-paranóico (p. 942). El arte pompier y el academicismo francés del XIX, pero también toda la tradición de la pintura, Brueguel, Vermeer, Böcklinm, Meissonier, los prerrafaelitas, Archimboldo... la nómina de Dalí coincidiría con el futuro canónico del arte fantástico (Lahuerta, 2013, p. 36). Recordemos que la exposición con la que Alfred H. Barr presenta en 1937 al movimiento en el MoMa llevará por título Fantastic Art, Dada, Surrealism. En palabras de Breton (2008) el Surrealismo supondría "un mundo accesible solo mediante la fantasía aplicando estrictamente la perspectiva central o utilizando como desconcertante instrumento generador de ilusiones ópticas con atmósferas de luces y sombras equilibradas, diamétricas o sobrenaturales" (p. 94).

Esta concepción de la imagen, y por extensión de la mirada occidental, habría sobrevivido incluso al cuestionamiento realizado desde las vanguardias clásicas de comienzos del siglo XX, perpetuándose con el desarrollo de técnicas analógicas y digitales de creación de imágenes como la fotografía, el cine, la televisión, el video o el ordenador (Mayer, 2018, p. 75). A pesar de su indiscutible éxito, la crisis sufrida por el medio pictórico a lo largo del siglo XX culminará con un cambio de paradigma en las enseñanzas artísticas tras el surgimiento del Arte Conceptual a principios de la década de los años setenta del siglo pasado. Al calificar al medio pictórico como ilusionista se desacreditaban no sus prácticas, sino el medio como estrategia para abolir la representación. El Arte conceptual señalará a su máxima expresión, el hiperrealismo como un subterfugio contra lo real al tratar de reproducir la realidad de la apariencia mediante un código basado en la fotografía (Foster, 2001, p. 145).

Pero la fotografía tampoco es ya aquel fiel testimonio de la realidad. Ese tiempo ha concluido, como señala Martín Prada (2018), "en la época de la imagen digital más que dar por supuesto en una fotografía su vinculación denotativa con el mundo siempre prevalece una presunta irrealidad" (p. 7). La pintura habría vuelto a ganar la batalla en el medio digital, donde puede crear desde la nada algo de apariencia completamente similar a lo que podría obtenerse mediante un registro fotográfico. La pintura digital encontraría en la tradición el lenguaje ilusionista que la industria del entretenimiento reclama.

Artistas contemporáneos como Guillermo Pérez Villalta, y con él gran parte de la Figuración Postconceptual española (De la Torre, 2012), se referirá a la pintura como el medio donde poder visualizar revelaciones absolutamente maravillosas que necesitan ser llevadas a la realidad (Pérez Villalta, 1995, p. 223), el modo de "representar lo imaginado, lo nacido de la invención, que no es real hasta que lo trae a este mundo “(Pérez Villalta, 1995, p. 223). Un asunto que interesa a los creadores de mundos de los videojuegos, y que habría provocado un inesperado resurgimiento de la pintura en el medio digital en las dos grandes tendencias que lideran el sector, la representación y la simulación (Acevedo, 2014). Especialmente significativa resultaría en el caso de la segunda, orientado a imitar lo real, pues "mientras que la representación intenta absorber la simulación interpretándola como falsa representación, la simulación envuelve todo el edificio de la representación tomándola como simulacro" (Baudrillard, 2005, p. 17-18).

Ahora bien, la explotación del efecto ilusionista de la imagen como realidad para provocar la inversión en el campo de la representación del espectador con fines políticos o económicos no es nada nuevo (Martín, 2018, p. 134). Un ejemplo ilustrativo serían los panoramas del siglo XIX, donde se exploraron las nuevas posibilidades para impresionar mediante el verismo de la pintura, su capacidad para presentar la experiencia de hechos y lugares lejanos en el espacio o el tiempo con una intención partidista (Martín, 2018 , p. 136). Una experiencia que recientemente, gracias a los avances tecnológicos, habría llegado a un nuevo paradigma en la realidad virtual.

Y será en este contexto donde la producción de videojuegos se ha posicionado como uno de los negocios más rentables de la industria del entretenimiento, demostrando que el deseo de vivir en el simulacro de estos mundos se habría convertido en el ocio preferido de la sociedad del capitalismo tardío. Según el informe anual de SuperData (2018) -donde se incluyen los videojuegos y gran parte de los medios que lo rodean- el mercado global del entretenimiento interactivo obtuvo en el año 2017 unos ingresos de 96.162 millones de 
euros. En España, según la Asociación Española de Videojuegos (AEVI) (2018), en 2017 facturaron 1.359 millones de euros, lo que supone más del doble que el cine, y casi seis veces más que la industria discográfica.

Cabría recordar que la responsabilidad del diseño de estos productivos mundos recae, en gran medida, en los concept artists. Circunstancia que ha motivado un creciente interés por su trabajo como demostrarían los numerosos lanzamientos en el sector del art book, publicaciones especializadas donde se recoge el trabajo de estos profesionales en el campo del videojuegos o películas de animación actuales, así como el trabajo inédito de gran número de profesionales para obras clásicas. Una nómina en la que podríamos descubrir al propio Dalí y sus trabajos para el Hollywood de los cincuenta. La visualización de imágenes mentales que proponían los surrealistas despertó el interés de directores como Disney y Hitchcock, y podríamos señalar sus trabajos para el proyecto Destino (Monféry, D., 2003) realizados en los años de la década de los años cuarenta como una de las grandes aportaciones de la vanguardia a la animación.

Si en el Renacimiento, "los artistas debían Ilusionar la existencia de personajes, objetos y espacios donde no había más que materia pictórica distribuida sobre un plano de dos dimensiones, superando su realidad material para sustentar la afirmación de otra realidad simulada" (Tomás, 2005, p. 203), ahora serán los concept artists los que afronten este reto durante la Sky Phase de la producción del videojuego. Esta etapa de exploración tiene como objetivo concretar las claves plásticas (Lilly, 2015, p. 22) del worlbuilding, proceso en el que se desarrolla el entorno imaginario provisto de historia y/o geografía propia. Unos mundos y narraciones construidos en los videojuegos, el teatro, la literatura, la pintura o el cine, con el objetivo de permitir a los jugadores "explorarlos y experimentarlos a través de sus medios específicos" (Planells, 2013, P. 153).

El caso que nos ocupa, Red Dead Redemption 2 (Rockstar Games, 2018), se ha convertido desde su lanzamiento (26/10/2018) en uno de los referentes en el campo de la simulación, llegando a facturar en el cuarto trimestre del año 516 millones de dólares (SuperData, 2018). Es interesante comprobar el gran éxito del producto, pero nuestro interés se centraría en comprobar la influencia de la pintura de la Hudson River School en la concepción del mundo que se presenta en el videojuego. Más allá de una cita o un referente, sus creadores habrían aprehendido una manera particular de visualizar el mundo del salvaje Oeste Americano. Un caso que, por sus características, podríamos comparar con la recreación del Oriente realizada por Gustav Moreau en una obra donde prescindiría de todo carácter realista, exótico o etnográfico (Forest, 2006, p. 19).

A pesar de las reticencias de la empresa Rockstar Games, el colaborador de Polygon Clayton Ashley (2018) establece una clara relación entre el estilo de la pintura paisajística de Hudson River School y las perspectivas de Red Dead Redemption 2. En cierto sentido, como señala David Pérez (2016), pensar la pintura "como discurso en el que algo acaece y, por ello, trastorna" pondría al descubierto "no solo como la imagen, en su propia hiperrealidad, sustituye y expropia a la realidad; sino también cómo lo visible no coincide necesariamente ni con lo visto ni con lo evidente" (p. 102). 


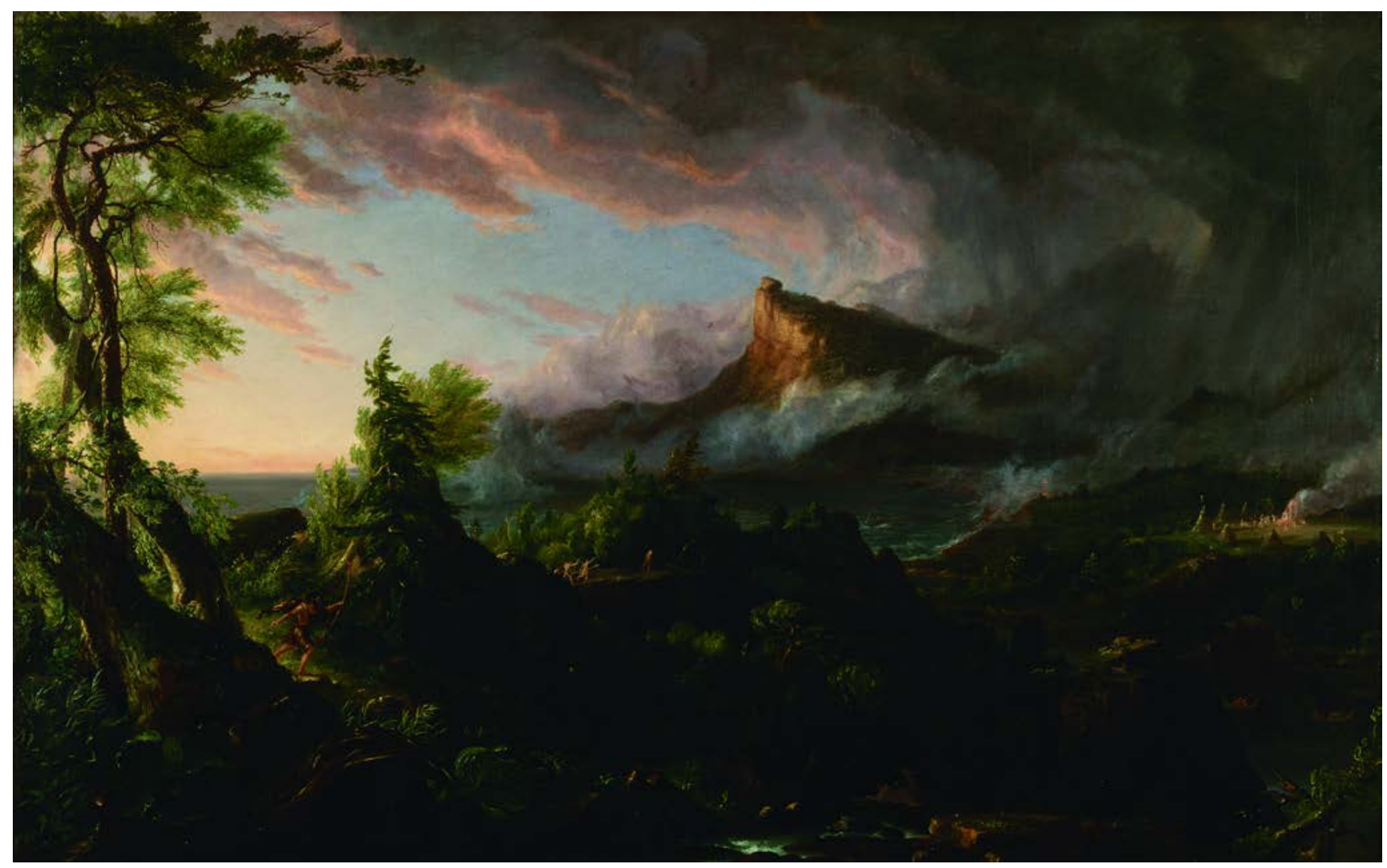

Figura 3. [Pintura], "El curso del imperio: El estado salvaje", Cole, T., 1836, 100 x 160 cm. (Fuente: https://en.wikipedia.org/wiki/Thomas_Cole. Sociedad Histórica de Nueva York. Dominio público de Estados Unidos).

Pero ¿Cuál sería la visión del Oeste Americano que aportó la Hudson River School? Esta fraternidad artística americana, conformada bajo la influencia del pintor inglés Thomas Cole (1801-1848) alrededor de 1850, aplicaría la teoría estética británica de lo sublime al paisaje estadounidense. Asher B. Durand, Frederic Church y Albert Bierstadt, entre otros, desarrollarán las claves del fundador con gran éxito hasta que, tras su muerte, y como consecuencia de la irrupción de la vanguardia francesa como referente artístico quedaría marginadas hasta su recuperación a mitad del siglo pasado (Avery, 2004). Cabe destacar la monumentalidad de algunas de sus obras, y el hecho de que las explotaran comercialmente en exposiciones itinerantes donde ofrecian al espectador la posibilidad de vivir una experiencia inmersiva a través de su superficie como una forma de transmitir su visión fantástica de la grandeza del paisaje del Oeste americano (Ashley, 2018).

El vicepresidente creativo de Rockstar Games, Dan Houser, ha declarado que Red Dead Redemption 2 ofrece una experiencia en sintonía con la naturaleza en un mundo que parece real (Goldberg, 2018). Una experiencia vivida en primera persona por el especialista Harold Goldberg (2018), y que describía como una perdida progresiva del ego para ser poseído por un mundo vivo y real hasta llegar a fusionarse con la naturaleza y el universo. Las claves estéticas de Turner y Constable, vía Cole y los iluministas Church y Bierstadt, son la base de la representación idealizada de esta naturaleza de carácter grandiosa que logra que un producto de vanguardia, realizado con tecnología de última generación, logre despertar nuevas emociones y sentimientos. Aaron Garbut, director de arte de Rockstar North, ha descrito este trabajo como la construcción, y no la representación lineal o estática, de un lugar. La simulación de "un mundo en constante cambio gracias a la implementación de numerosos sistemas en iluminación, cámaras, clima y hora del día" (Gies, 2018) que se relacionan con las acciones del jugador. La clave de este logro se encontraría en una iluminación inspirada en la perspectiva aérea, potenciada por una novedosa tecnología con mayor poder de simulación en los gradientes de profundidad o los fenómenos atmosféricos, como la niebla y la humedad. 


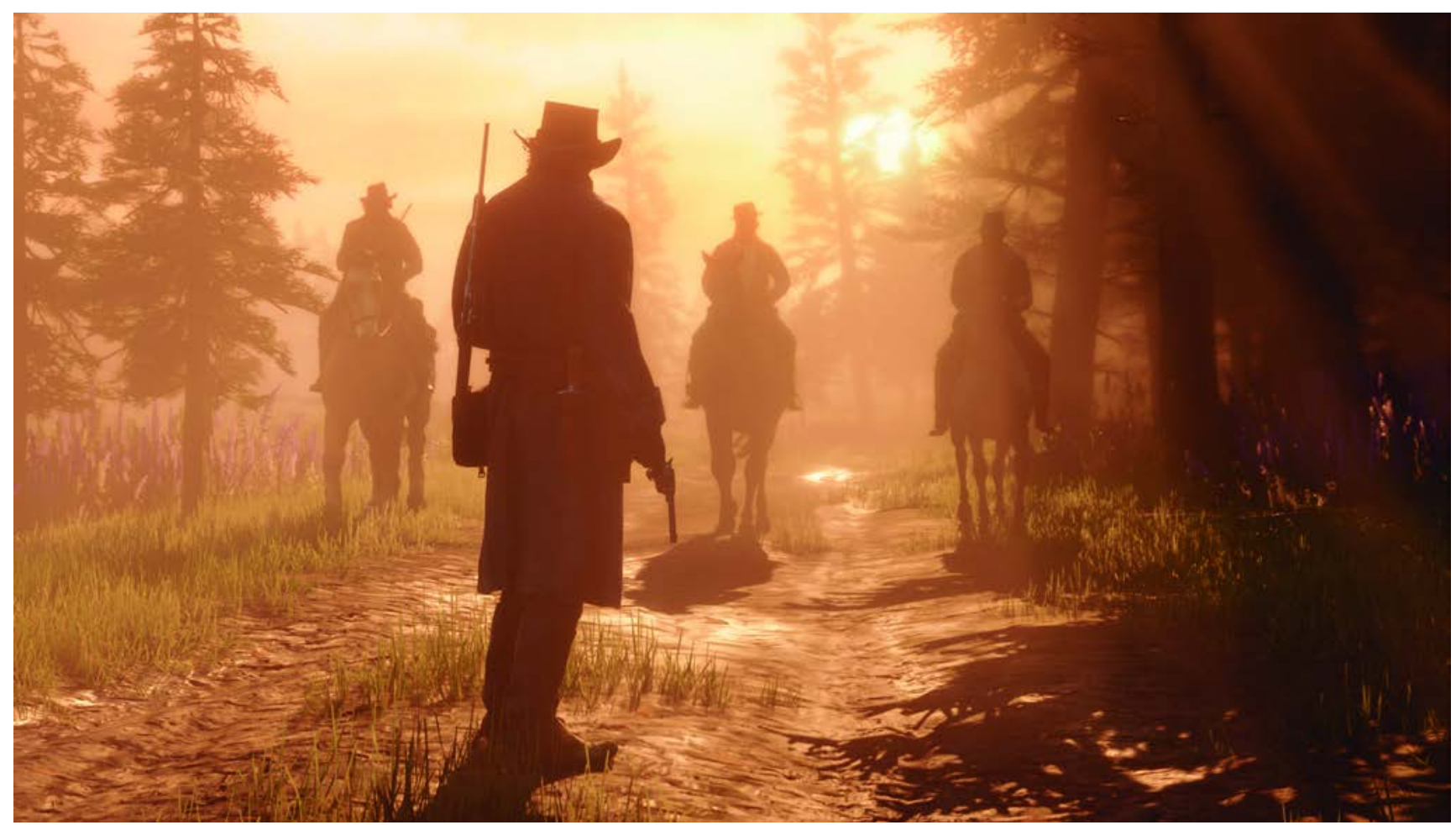

Figura 4. [Captura de pantalla], “Red Dead Redemption 2”, Rockstar Games, 2018. (Fuente: https://www.igdb.com/games/red-dead-redemption-2/presskit).

\section{CONCLUSIONES}

Al analizar Red Dead Redemption 2 podemos comprobar la capacidad de la pintura para crear conceptos a través de claves estéticas, más allá de la representación o el simulacro. La particular visión del salvaje Oeste Americano que presenta la pintura de la River Hudson School ha sido la base para la creación de una de las experiencias más sorprendentes y vanguardistas en el competitivo campo del videojuego. La pintura ilusionista ha generado a lo largo de su historia un conocimiento teórico y estético que la protegería de cualquier ataque, y asegura su vigencia y desarrollo en nuevos medios como el digital.

Actualmente, los concept artists, y los profesionales de la imagen digital, reclaman la enseñanza de este conocimiento en los centros de formación artística. Y, como podemos comprobar, los actuales programas de las diferentes facultades de Bellas Artes en España no están prestando, aparentemente, la atención debida a sus necesidadess favoreciendo la oportunidad de negocio para másteres especializados. La demanda de profesionales que sean capaces de visualizar imágenes de otros mundos es creciente por parte de la industria del entretenimiento, y será cada vez mayor porque, como señalaba Debord (1999), "La cultura íntegramente convertida en mercancía debe a su vez convertirse en la mercancía estelar de la sociedad espectacular" (p. 159).

\section{FUENTES REFERENCIALES}

Acevedo, A. (05, febrero, 2014). Simulación y Representación en los videojuegos ¿Dos tendencias?. Zehngames.com. Recuperado de http://www.zehngames.com/thinkpieces/simulacion-y-representacion-en-los-videojuegos-dos-tendencias

Asociación Española de Videojuegos (AEVI) (2018). Anuario 2017. Anuario de la Industria del Videojuego. Recuperado de http://www.aevi.org.es/web/wp-content/uploads/2018/07/AEVI Anuario2017.pdf

Ashley, C. [Polygon.com]. (2018). How Red Dead Redemption 2's landscapes are connected to 19th century art. [Archivo de video]. Recuperado de https://youtu.be/AOXbWUEvOHo

Avery, K. J. (2004). The Hudson River School. En Heilbrunn Timeline of Art History. New York: The Metropolitan Museum of Art. Recuperado de http://www.metmuseum.org/toah/hd/hurs/hd hurs.htm 
De la Torre Oliver, Francisco

Imágenes de otros mundos. La alianza entre pintura y videojuego.

IV Congreso INTERNACIONAL DE INVESTIGACIÓN EN ARTES VISUALES ANIAV 2019

IMAGEN [N] VISIBLE]

http://dx.doi.org/10.4995/ANIAV.2019.9013

Baudrillar, J. (2005). Cultura y simulacro. Barcelona: Kairos.

Bierstadt, A. 1868. Entre la Sierra Nevada, California. [Pintura]. Fuente: https://commons.wikimedia.org/wiki/Albert Bierstadt. Dominio público de Estados Unidos.

Breton, A. (1985). Manifiestos del surrealismo. Barcelona: Labor.

Cole, T. (1836). El curso del imperio: El estado salvaje [Pintura]. Fuente: https://en.wikipedia.org/wiki/Thomas Cole. Sociedad Histórica de Nueva York. Dominio público de Estados Unidos.

Chion, M. (2003). David Lynch. Barcelona: Paidos.

Dalí, S. (2003). Diario de un genio. En Dalí, S. Obras completas. Textos autobiográficos (925-1184). Barcelona: Destino.

De la Torre Oliver, F. (2012). Figuración Postconceptual. De la Nueva Figuración madrileña a Neometafísica (1970-2010). Valencia: Fire Drill.

Disney, R. E. y Bloodwort, B. (productores), Dominique Monféry (director). (2003). Destino. E.U.: Walt Disney Pictures.

Debord, G. (1999). La sociedad del espectáculo. Valencia: Pre-textos.

Forest, M. C. (2006). El sueño de Oriente. En Gustave Moreau. Sueños de Oriente (8-19). Madrid: Fundación Mapfre.

Foster, H. (2001). El retorno de lo real. Barcelona: Akal.

Goldberg, H. (15, octubre, 2018). How the West Was Digitized. The making of Rockstar Games' Red Dead Redemption 2. New York Magazine. Recuperado de https://www.vulture.com/2018/10/the-making-of-rockstar-games-red-dead-redemption-2.html

Gies, A. (14, diciembre, 2018). The painted world of Red Dead Redemption 2. Polygon.com. Recuperado de https://www.polygon.com/red-dead-redemption/2018/10/26/18024982/red-dead-redemption-2-art-inspiration-landscape-paintings

Goodman, N. (1990). Maneras de hacer mundos. Madrid: La Balsa de la Medusa.

Goodman, N. (1995). De la mente y otras materias. Madrid: La Balsa de la Medusa.

Gubern, R. (1996). Del bisonte a la realidad virtual: la escena y el laberinto. Barcelona: Anagrama.

Heidegger, M. (1996). La época de la imagen del mundo. En Heidegger, M. Caminos del bosque (63-78). Madrid: Alianza.

Jiménez, J. (2013). El surrealismo y el sueño. En El Surrealismo y el sueño (18-54). Madrid: Museo Thyssen Bormenisza.

Lahuerta, J. J. (2013). Sobre la retroactividad surrealista. En Surrealismo antes del surrealismo (20-55). Madrid Fundación Juan March.

Lilly, E. (2015). The Big Bad World of Concept Art for Video Games. Culver City: CA Design Studio Press.

Martín Prada, J. (2018). El ver y las imágenes en el tiempo de Internet. Barcelona: Akal.

Mayer, M. (1996). Un cambio de perspectiva. En Máquinas de Mirar (75-100). Sevilla: Centro Andaluz de Arte Contemporáneo.

Planells de la Maza, A. J. (2013). Los videojuegos como mundos ludoficcionales. Una aproximación semántico-pragmática a su estructura y significación. (Tesis doctoral). Universidad Carlos III. Madrid.

Pérez, D. (2016). Desfigurar. Pintura contra imagen. Imagen contra pintura. En De la Torre, P. \& Mestre, J. (Eds.) A través de la Pintura. (102-117). Valencia: Firedrill.

Pérez Villalta, G. (2011). Las metamorfosis y otras mitologías. Málaga: Centro de Arte Contemporáneo.

Pérez Villalta, G. (1995). Guillermo Pérez Villalta. Sevilla: Junta de Andalucía.

Rockstar Games (desarrolladora) y Garbut, A. (artista). (2018). Red Dead Redemption 2 [videojuego]. EU.: Rockstar Games.

Rockstar Games, 2018, Red Dead Redemption 2, [Captura de pantalla], Fuente: https://www.igdb.com/games/red-dead-redemption$\underline{2 / \text { presskit }}$ 
Sánchez Coterón, L. (2012). Arte y Videojuegos: mecánicas, estéticas y diseño de juegos en prácticas de creación contemporánea. (Tesis Doctoral). Universidad Complutense. Madrid,

Silver, J. (productor) y Wachowski, L., Wachowski, L. (directoras). (1999). Matrix [Cinta cinematográfica]. EU.: Warner Bros / Village Roadshow Pictures / Groucho II Film Partnership.

Superdata (2018). Market Brief. 2018 Digital Games \& Interactive Entertainment Industry Year In Review. Recuperado de https://www.superdataresearch.com/market-data/market-brief-year-in-review/

Tomás, F. (2005). Escrito, pintado. Madrid: La balsa de la Medusa.

Wolf, M. J. P. (2012). Building imaginary words. The theory and history of subcreation. Nueva York: Routledge. 